\title{
Effects of Poor Leadership Styles in Lubombo Secondary Schools
}

\author{
Milton Dlamini Racheal Mafumbate* \\ University of Eswatini, Department of Educational Foundations and Management, Faculty of Education.
}

\begin{abstract}
The purpose of this study was to explore effects of poor leadership styles in the Lubombo secondary schools. Its objectives were to establish how the head teachers leadership styles affect the academic performance of learners in the secondary schools in the Lubombo region; and to establish ways in which head teachers can improve their leadership styles in the secondary schools in the Lubombo region. The study adopted a qualitative approach and case study design. Purposeful sampling was used to select a sample of 36 participants comprising 30 teachers, 3 deputy head teachers and 3 head teachers. The researcher used semi-structured interview, focus group discussions and observation as tools of data collection. The study revealed that using democratic leadership styles gives the teachers a chance to share their views making them feel valued leading to good performance. Poor leadership leads to failure of students at the school. The role of head teachers as leaders is thus a critical factor in determining implementation of school programmes. Also good leadership encourages good discipline leading to good performance. The findings showed that the head teacher needs to avoid using force on teachers and should be a role model to the teachers and work together to improve the performance of the school. The findings revealed that regular training through workshops, in-service training and self -upgrading would help in improving the head teachers' leadership styles.
\end{abstract}

Keywords: Leadership, leadership styles, discipline head teacher, management.

DOI: $10.7176 /$ RHSS/9-24-02

Publication date: December $31^{\text {st }} 2019$

\section{Background}

In many parts of the world, there is increasing recognition that schools require effective leaders and managers if they are to provide the best possible education for their students and learners (Bush, 2009). Governments are realizing that their main assets are their people and that becoming competitive depends increasingly on the development of a highly skilled workforce. This requires trained and committed teachers who in turn need good leadership. The quality of leadership makes a significant difference in schools and student outcomes (Bush, 2009). In supporting this Crum \& Sherman (2008) stated that principals need to provide highly valued insight into their daily styles fostering an environment supportive of high teacher performance.

The primary responsibility of the principal is to facilitate effective teaching and learning with the overall mission of enhancing student academic achievement. The overall management of schools rests with principals, working with and through the teachers to make best use of their capabilities in the profession and achieve the desired educational goals. The principal has a vital responsibility in discharging managerial duties in the school. The principals being the educational leaders are in good position to supervise, monitor, assess, evaluate and spread up to date information on educational issues and current teaching techniques to arouse teachers so as to achieve higher students' academic performance. Principal leadership styles and types in school management influence the activities of the school. Kythreotis, Pashiardis and Kyriakides (2010) concluded that the principal leadership style and types affect students' academic achievement. The success of any organization only depends upon the way and manner in which the leader operates within the organization. The type of leadership adopted in leading the group will determine the leader. A leader behaviour is what makes the difference between effective and ineffective organizations (Kythreotis, Pashiardis \& Kyriakides, 2010).

In Western countries such as Canada, Britain and the USA various studies have been conducted to ascertain if leadership styles in schools have an impact on student performance. Research studies in the USA show that school leadership is likely to have more positive impact on student achievement and well-being when it is able to focus on the quality of learning, teaching, and teacher learning (Robinson, Lloyd \& Rowe, 2008). The leadership that ensures an orderly and supportive environment makes it possible for staff to teach and students to learn. Protection of teaching time from administrative and students disruption is one critical aspect of this dimension.

Another aspect is creating classroom and playground environment in which both staff and students feel respected and personally cared for. The issue of principal and leadership accountability is further demonstrated by Militello, Fusarelli, Alsbury and Warren (2013) in the United States where, in the event of failing or poor success rates in schools, principals are held accountable and they run the risk of being removed from the school as principals. Within this context, it shows that accountability is vested with the principal who is the leader of the school.

Similarly, the importance of school leadership for school effectiveness and school improvement has been a 
subject of research throughout different countries. Some evidence from Pakistan by Salfi (2010) found the quality of school leadership as one of the major factors with significant impact upon school effectiveness and school improvement. Hence effective leaders exert an indirect but powerful influence on school effectiveness and students' achievement. Salfi (2010) also noted that principals play a key role in establishing cultures that are professionally stimulating for teachers increasing their sense of efficacy and beliefs that have the capacity to make a difference in students' learning. In a study by Robinson, Lloyd and Rowe (2007) in New Zealand it was concluded that school leadership is likely to have more positive impact on students' achievement and well-being when it is able to focus on the quality of learning, teaching, and teacher learning. Taken collectively the effective schools studies reflected the view that the direct responsibility of improving instruction and learning rests in the hands of the school head (Mwape, 2013).

According to Organization for Economic Cooperation and Development (OECD) (2013), the concepts of leadership, management and administration overlap and have been accorded different emphases over time and in different contexts. Their usage varies across countries and professional cultures. In English-speaking countries such as Australia, Canada, New Zealand, the UK and the US, the role of a leader is seen as of prime importance in raising standards and promoting school improvement, but this is not so in other countries, for example the Netherlands and Scandinavian countries. This difference in emphasis reflects variations in the functioning of education systems and their historical, national and regional policy contexts that will exert different degrees of influence on institutions' work and therefore on the role of leaders in schools.

In West Africa research in Ghana by Minadzi and Nyame (2016), concluded that the actions and in-action of a principal in one way or the other influence the performance of teachers in the classroom and by extension in the school. Furthermore, leadership types and styles have some effects on the performance of teachers. This is because when there is a strained relationship between staff, it retards the progress of the instruction since morale would be very low and that would result in apathy.

In the Southern African Development Community (SADC) region, Wamba and Mwalughali (2013) point out that in Malawi most appointed head teachers do not receive training. The Ministry of Education appoints head teachers based on a successful teaching career as demonstrated by their student's achievement on the national test. Wamba and Mwalughali (2013) also found out that lack of school leadership preparation programmes prevents Malawi to reach its education Millenium Development Goals and carries implications for NGOs working in the education sector. Moreover, research on the preparation of school leaders is sparse and almost non-existent in Malawi.

A study in South Africa, by Tilley (2011), reviewed the leadership type of principals in high-performing schools in extreme poverty areas to determine what factors accounted for academic achievement. The study revealed that school leadership that had high expectations for staff members and emphasized small group instruction, collaboration, and continuous improvement in instructional practices, played a significant role in student academic achievement.

In Eswatini, according to the Ministry of Education and Training (MoET) (2016), head teachers are responsible for the day to day management of the entire school and were trained by in-service education and training department (INSET). MoET (2016) adds that one of the objectives of INSET was to provide head teachers with on-going training in managerial skills in order to improve the quality of education in schools. According to the Ministry of Education's guide to school regulations and procedures (1981), the head teacher is responsible for the supervision and control of the work of the teachers and pupils in the school and to work effectively. He/she must attend to matters which are connected with planning, recording done by teachers and the quantity and quality of written work done by the pupils. The role which the principals and educational managers in Eswatini play pertaining to managerial involvement is highlighted by Mazibuko (2007) who indicated that principals should be involved as managers in the community they serve, as administrative and functional managers in the school per se, and also be more involved with the learners to ascertain that they truly grasp the educational environment they serve in order to make effective managerial decisions.

The conclusion reached is that leadership is a key element of team development and organizational development. Leadership is one of the significant factors for school effectiveness and successful schools are associated with the activities of effective leadership. However, it has been noted that little has been said about head teachers' leadership styles in the Lubombo region and how it affect the learners' academic performance. There is a knowledge gap that exists that needs to be filled through research. It is against this background that the researcher decided to conduct this study.

\section{Objectives of the study}

The study sought to:

- $\quad$ establish how the head teachers leadership styles affect the academic performance of learners in the secondary schools in the Lubombo region; and

- $\quad$ establish ways in which head teachers can improve their leadership styles in the secondary schools in the 
Lubombo region.

\section{Theoretical framework}

This study was guided by the Fiedler's contingency theory of leadership. The contingency approach to leadership proposes that effective leadership cannot be explained by any one factor. Instead, it proposes that all factors must be considered in the context of the situation in which the leader finds himself (Lunenburg \& Ornstein, 2007). According to Northouse (2007), Fiedler developed contingency theory by studying the styles of many different leaders who worked in different context, primarily military organisations. As a result, Fiedler was able to empirical give grounded generalizations about which style of leadership was best and which styles were worse for a given organizational context (Northouse, 2007). Fiedler categorized leadership as task motivated and relationship motivated. Task motivated leaders are concerned primarily with reaching a goal, whereas relationship motivated leaders are concerned with developing close interpersonal relationships.

Fiedler's contingency theory emphasized the leader's personality, or psychological disposition, is a main variable in her/his ability to lead, and said that how the group receives the leader, the task involved, and whether the leader can actually exert control over the group are the three principle factors that determine how successful the leader-led arrangement will be (Fiedler, 1958). Thus, the values from the least preferred co-worker (LPC) are added and then averaged to produce the score. A high LPC score, as can be seen from the example, exhibits a positive orientation towards human relations. S/he gets along with people (Fiedler, 1958). The nature of the task is less important and issues in doing it may be compensated for with good human relations. When the environment is such that each group member is independent, such as in a scientific setting, tasks may not be all that well defined, and a leader must rely more on her or his personality to accomplish goals (Fiedler, 1958).

The contingency theory of leadership by Fiedler (1958) has been preferred in this study because it advocates for the teacher to use appropriate leadership styles depending on the situation. According to Hoy and Miskel (2008), the contingency theory states that leadership effectiveness is said to be dependent upon many variables. Therefore the theory argues that a specific trait under a particular situation makes a particular leaders effective. The same trait in another situation may make the leader in effective. This theory was the most applicable for this study as it helped to show how effective leadership and performance depends on the head teacher leadership style.

\section{Methodology}

The study followed a qualitative approach and the case study design. The researcher preferred a case study design because a small sample was needed from only three schools where in-depth information was needed. Because the phenomenon at hand is a complex social phenomenon the researcher found it suitable to use case study research. Creswell (2014) defines a case study as a qualitative approach that explores a real-life contemporary bounded system (a case) or multiple bounded systems overtime, through detailed, in-depth data collection involving multiple sources of information and reports a case description and case themes. This means that the researcher explores in-depth programme, event, activity, or one or more individuals.

The researcher used 36 participants for the study comprising of 30 teachers, 3 head teachers and 3 deputy head teachers. Purposive sampling was used for selecting the sample for this study. The researcher developed an inclusion criteria which was that the participants should be from the poor performing schools and also they should be willing to share information. Purposive sampling method helps to choose in an appropriate manner, the restricted set of participants (Bless \& Higson-Smith, 2009). The purposive sampling method was chosen because the researcher was concerned with the relevance of the sample in the sense that only the sample that could have detailed information on impact of leadership style on teacher's performance and implications on students' academic performance.

Focus group discussions and observations were used as data collection methods suitable for qualitative research.

\section{Results and discussion}

\subsection{The effects of head teachers' leadership styles and academic performance of learners}

The findings showed that using democratic leadership styles gives teachers a chance to share their views making them feel valued and thus work hard for good performance. The findings agree with Jumba (2017) who also recommended that the school head teacher should adopt a democratic style of leadership as it tends to help build preventative discipline and minimizes corrective discipline. The leadership style that involves teachers supports them and closely monitors the teachers to ensure their welfare encourages good discipline at school. The findings concurred with Garg and Ramjee (2013) who said that democratic leadership is positively related to continuance commitment and suggests that the leader with democratic leadership style will build trust and empathizing on development with employees.

The findings revealed that good leadership leads to good performance while poor leadership leads to failure. Also the use of instructional leadership ensures good monitoring of teaching and learning and also encourages 
punctuality among teachers and learners. An open climate creates a conducive learning environment and good relations with learners leading to good performance. The findings agree with Kabeta, Manchishi and Akakandelwa (2015) who associates school leadership with the quality of learning and teaching, the motivation of teachers and the ethos of the school. The operative notion is that the quality of teaching and learning is largely dependent upon an individual or group that exercises supervisory responsibility.

The findings showed that good head teacher's leadership helps to create a conducive learning environment encouraging hard working among learners leading to good performance. Also good leadership encourages good discipline which leads to good performance. The finding agree with Robinson, Hohepa and Wahlstrom (2009) who reported that there is now a growing body of research evidence which reveals that the successful distribution of leadership depends on the establishment of trust. Trust is closely associated with a positive school ethos improved conditions for teaching and learning, an enhanced sense of teacher autonomy in the classroom and sustained improvement in students behaviour, engagement and outcomes.

The findings of the study showed that the head teacher needs to avoid using force on teachers and should be a role model to the teachers and work together to improve the performance of the school. Also in order to improve leadership styles the head teachers need to be flexible to allow the teachers to make own decisions on the best instruction but then take control of everything. The findings partly agree with Louis, Dretzke and Wahlstrom (2010) who suggest that successful head teachers use the same basic leadership practices. It is the way in which leaders apply leadership practices, rather than the actual practices themselves, that demonstrates their ability to respond to the context in which they work.

\subsection{Improving head teachers leadership styles in the secondary schools}

The findings revealed that regular training through workshops, in-service training and self -upgrading would help in improving the head teachers' leadership styles. Also regular professional development through training and personal learning were essential in improving the head teachers' leadership styles. The findings agree with Andende (2016) who recommended that head teachers' leadership styles needed to be improved through holding workshops to capacity built them to increase their morale and performance in schools.

The findings revealed that using a variety of leadership styles to fit in a situation would help in improving the head teachers' leadership style. Also effective or improvement of head teachers' leadership style needs setting clear policies which should be followed strictly and everyone should be treated equally. The findings showed some similarities with a study by Tibagwa, Onen and Oonyu (2016) who recommended that school heads should make use of appropriate leadership styles to suit situations, needs and developmental aspirations of teachers as well as the needs of schools they serve

\section{Conclusions and recommendations}

The study concluded that head teachers' leadership styles practices in some schools in the Lubombo region include democratic leadership and autocratic leadership. Findings revealed that the use of autocratic leadership in some schools led to lack of cooperation and resistance which affected the normal teaching and learning process leading to poor performance. Teachers do not like autocratic leadership because they are also professionals like the head teacher. However instructional leadership was rarely used because the head teachers spend most of their time on administrative work. The study also concluded that the democratic leadership style leads to satisfying decisions and some head teachers preferred it because they relied on the staff's views.

It was also concluded that flexible leadership styles satisfy followers, enhance discipline, create a conducive learning environment and also contribute to good performance. The results indicate that unclear and poor leadership styles lead to poor school management, misuse of power, poor performance and slow progress of the school. The study concludes that improving head teachers leadership style needs flexibility, motivation, professional development and regular training.

Based on the findings and conclusions drawn from this study the following recommendations were made:

- School head teachers' should be flexible on their leadership and they should always practice the leadership that accommodated everyone. When people in any context participate in shaping the direction of the organization their capacity is enhanced. Meaningful structures and processes should be in place to facilitate participation and responsibility need to be shared throughout the organization.

- Ministry of Education and Training should empower head teachers on how to improve in their leadership styles. They should do regular monitoring of the head teachers and ensure they use the leadership styles that help their school to progress and perform well.

- The Ministry of Education and Training should offer regular workshops and in-service training for head teachers and deputy head teachers on ways to be effective leaders. They should train them on the modern leadership trends that accommodates the modern generation.

- The head teachers and deputy head teachers should spare some of their resources to take some leadership training courses to upgrade their knowledge and enhance personal professional development. They should 
do regular studying and researches on how to improve their leadership styles.

- Teacher training colleges and all the institutions of higher learning should train teachers and make sure they include leadership courses which should be mandatory for all training teachers.

- The policy makers should make new policies that govern head teachers and deputy head teachers' leadership. The policies should be flexible and allow the head teachers to use different leadership styles depending on the situation they are facing.

- Head teachers and deputy head teachers should have internal school policies which should be made by all school stakeholders. They should also make sure the teachers and learners know about the internal policies and the consequences of not complying

\section{References}

Andende, N. (2016). Head teachers' leadership styles and their effects on teachers' morale in selected primary schools of Zambezi district in the north- western province of Zambia. A Dissertation Submitted to the University of Zambia in Partial Fulfilment of The Requirements for the Award of the Degree of Master of Education in Educational Administration and Management.

Bashiru, S., B., A. (2013). Assessing the impact of leadership styles of head teachers on academic performance: A case study of selected schools in the Manhiyia Sub-Metro. M .A. Thesis. Kwame Nkrumah University of Science and Technology.

Bisman, J., E. \& Highfield, C. (2012). The road less travelled: An overview and example of constructivist research in accounting. Australian Accounting, Business and Finance Journal 6 (5): 3-22. University of Wollongong.

Bless, A. \& Higson-Smith, C. (2009). Fundamentals of social research methods: An African perspective. Cape Town: Juta.

Bush, T. (2009). Theories of educational leadership and management. London: Sage Publications.

Chance, P. \& Chance, E. (2002). Introduction to educational leadership and organisation behaviour theory. New York: Eye on education, Inc.

Creswell, J., W. (2014). Educational Research: Planning, Conducting and Evaluating Quantitative and Qualitative Research. Lincoln: Prentice Hall.

Crum, K., S. \& Sherman, W., H. (2008). Facilitating high achievement high school principals' reflections on their successful leadership practices. Journal of Educational Administration, 46 (5), 562-580.

Eissa, A., Brown, D. \& Wiseman, A. (2013). The effects of principal Leadership styles on school environment and outcome.-Kuwait.

Examination Council of Eswatini. (2016). Management of the FEP in general. Ministry of education and Training. Mbabane.

Fiedler, F. (1958) Fiedler's contingency theory. Retrieved from https://www.leadership- central.com/fiedler'scontingency-theory.html.

Garg, A., K., D. \& Ramjee, D. (2013). The Relationship between Leadership Styles and Employee Commitment at a Parastatal Company in South Africa. International Business \& Economics Research Journal, 12(11) 1411-1436.

Hoy, W., \& Miskel, C., G. (2008). Education administration: Theory, Research and Practice. $9^{\text {th }}$ Ed. New York: McGraw Hill.

Jumba, I. (2017). Influence of head teachers' leadership styles on students discipline in public secondary schools in Nairobi province, Kenya. 1st Annual International Conference on Research and Innovation in Education.

Kabeta, R., M., Manchishi, P., C. \& Akakandelwa, A. (2015). Instructional Leadership and Its Effect on the Teaching and Learning Process: the Case of Head teachers in Selected Basic Schools in the Central Province of Zambia. International Journal of Science and Research (IJSR) ISSN (Online): 2319-7064, Volume 4 Issue 4.

Kingdom of Eswatini (2011). Ministry of Education and Training. Education and Training Sector Policy. Mbabane. Websters.

Kythreotis, A., Pashiardis, P., \& Kyriakides, L. (2010). The influence of school leadership styles and school culture on students' achievement in Cyprus primary schools. Journal of Educational Administration, Vol. 48 No. 2 , pp. 218-240.

LaMarco, N. (2017). The Advantages of Fiedler's Contingency Model. Retrieved from https://smallbusiness.chron.com/advantages-fiedlers-contingency-model-18368.html.

Leiter, A. (2007). Concept leadership and management within the manufacturing industries. Munich GRIN Verlag Publishers.

Louis, K., S., Dretzke, B. \& Wahlstrom, K. (2010) 'How does leadership affect student achievement? Results from a national US survey'. School effectiveness and school improvement, 21 (3) 315-336.

Lunenburg, F., C. \& Ornstein, A., C. (2007). Educational administration: Concepts and practices.Vol.13. $5^{\text {th }}$ Ed. Belmont: Thomson Brook/ Cole. 
Mazibuko, S. P. (2007). The managerial role of the principal in whole-school evaluation in the context of disadvantaged schools in KwaZulu-Natal M A. Thesis. University of South Africa. Pretoria

.Mcmillan, J., H., \& Schumacher, S. (2010). Research in Education: Evidence-based inquiry. New York: Pearson.

Mdluli, A. (2016). Another poor performance in external examinations. Times of Swaziland, Mbabane January.

Minadzi, V., M. \& Nyame, G. (2016) Leadership Styles Of Basic School Head Teachers: How Does It Influence Teachers' Classroom Performance? The International Journal of Social Sciences and Humanities Invention Volume 3 issue 4 pg. 1983-1991.

Minisrty of Education and Training (2016). Education and training sector policy. The Kingdom of Eswatini. Mbabane.

Ministry of Education and Training (1981). School regulations and procedures. The Kingdom of Eswatini. Mbabane.

Mwape, K., (2013). A Survey of Head teacher's leadership and their effects of School Climate in selected schools in Northern Province. M.Ed. Dissertation. Lusaka: University of Zambia.

Northouse, P., G. (2007). Leadership: Theory and practice. $3^{\text {rd }}$ Ed. Thousand Oaks, CA: Sage.

Robinson, V., Hohepa, M. \& Lloyd, C. (2009) School leadership and student outcomes: Identifying what works and why. Best Evidence Syntheses Iteration (BES). New Zealand: Ministry of Education. Retrieved from: http://www.educationcounts. govt.nz/publications/series/2515/60169/60170.

Salfi, N., A. (2010). Successful leadership practices of head teachers for school improvement. Journal of Educational Administration, Vol. 49 No. 4, pp. 414-432.

Tibagwa, K., N., Onen, D. \& Oonyu, J. (2016). Head Teacher's Leadership Styles and the Quality of Teacher Support Supervision. $\quad$ Retrieved from https://www.researchgate. net/publication/307923862_Head_Teacher's_Leadership_Styles_and_the_Quality_of_ Teacher_Support_Supervision.

Tilley, T.B. (2011). Success despite socio-economics: A case of a high achieving, high poverty school. Lynchburg: Liberty University.

Wamba, N., \& Mwalughali, M. (2013). A grassroots assessment of educational challenges in Luwinga ward schools in Mzuzu, Malawi. Mzuzu: Mzuzu University Press 